\title{
Touch, Caring, and Cancer: randomized controlled trial of a multimedia caregiver education program
}

\author{
William Collinge • Janet Kahn • Tracy Walton • \\ Leila Kozak • Susan Bauer-Wu • \\ Kenneth Fletcher • Paul Yarnold • Robert Soltysik
}

Received: 14 February 2012 / Accepted: 27 November 2012 /Published online: 21 December 2012

(C) The Author(s) 2012. This article is published with open access at Springerlink.com

\begin{abstract}
Purpose A randomized controlled trial was conducted to evaluate outcomes of a multimedia instructional program for family caregivers in simple touch-based techniques to provide comfort to cancer patients at home.
\end{abstract}

\author{
W. Collinge $(\triangle)$ \\ Collinge and Associates, 3986 N Shasta Loop, \\ Eugene 79405 OR, USA \\ e-mail: william@collinge.org \\ J. Kahn \\ Integrative Consulting, 240 Maple St., \\ Burlington, VT 05401, USA \\ T. Walton \\ Tracy Walton \& Associates, LLC 10 Sargent Street, \\ Cambridge, MA 02140, USA \\ L. Kozak \\ Center of Excellence in Outcomes Research in Older Adults, \\ VA Puget Sound Health Care System HSR\&D, VAPSHCS, \\ 1100 Olive Way, Suite 1400 (S-152), \\ Seattle, WA 9810, USA \\ $\mathrm{S}$. Bauer-Wu \\ Woodruff School of Nursing, Emory University, \\ 1386 Normandy Dr., \#4, \\ Atlanta, GA 30306, USA \\ K. Fletcher \\ Department of Psychiatry, \\ University Massachusetts School of Medicine, 65 Darnell Road, \\ Worcester, MA 01606-3406, USA \\ P. Yarnold \\ Optimal Data Analysis, \\ LLC 1220 Rosecrans St., \#330, \\ San Diego, CA 92106, USA \\ R. Soltysik \\ Independent Consultant, 213 N St. SE, \\ Glen Burnie, MD 21061, USA
}

Methods A multilingual 78-min DVD and 66-page manual were produced for homebased instruction. Content addresses attitudes and communication about touch in cancer, psychological preparation for giving and receiving touch, safety precautions, massage techniques for comfort and relaxation, acupressure for specific cancer-related symptoms, and practice in the home setting. Materials were produced in English, Spanish, and Chinese versions. A community-based multiethnic sample of 97 adult patient/caregiver dyads was randomized to experimental (massage) or attention control (reading) groups for 4 weeks. Massage dyads received the program and instructions to practice at least three times per week, while control caregivers read to their patients for the same frequency. Self-report instruments assessed change in symptom severity, quality of life, perceived stress, and caregiver attitudes.

Results Significant reductions in all symptoms occurred for patients after both activities: $12-28 \%$ reductions after reading vs. $29-44 \%$ after massage. Massage caregivers showed significant gains in confidence, comfort, and self-efficacy using touch and massage as forms of caregiving.

Conclusions Multimedia instruction in touch and massage methods may offer family members a viable means of enhancing self-efficacy and satisfaction in caregiving while decreasing patient pain, depression, and other symptoms. Family members may be able to learn and apply safe and simple methods that increase patient comfort and reduce distress.

Keywords Caregiver education · Oncology massage · Palliative care $\cdot$ Psychosocial oncology $\cdot$ Family caregivers

\section{Introduction}

Touch in the form of massage and other gentle, noninvasive methods is one of the most popular forms of palliative care for relief of pain and other symptoms in cancer. Numerous studies 
of massage with cancer patients have demonstrated significant effects on perceived stress $[1,2]$, quality of life [3-6], and common symptoms such as pain, nausea, anxiety, mood disturbance, fatigue, and disturbed sleep [7-17]. Impact can be both immediate and clinically significant; in a study of 380 adults with advanced cancer, both massage and simple touch were found to bring immediate improvement in pain and mood [18], and a large study of 1,290 patients found a single massage to reduce symptom levels by $21-52 \%$ [19].

Touch-based methods of comfort are offered in many cancer treatment centers, hospice programs, and other palliative care settings [20,21]. However, there are significant obstacles to wide use and consistent delivery to patients over time, often resulting in such therapy being a novel or special event outside routine care. For many, the cost of such services and lack of insurance coverage makes regular use unaffordable. For those with the means, treatment settings often lack sufficient availability of personnel who are trained or have time to deliver this form of care. For home-based patients, to visit a provider requires travel from home and the scheduling of appointment times into the future - both of which can be problematic for patients carrying high burdens of distress.

The integration of touch as routine supportive care may be achievable through tapping an underutilized resource in the patient's natural social environment: family members and friends who have the need and desire to contribute to relief of suffering in their loved one. Numerous studies have found that care partners, often due to perceived helplessness or low self-efficacy in contributing to the well-being of the patient, can experience as much or even more distress than cancer patients [22-28]. There is also evidence that care partners benefit from doing active, hands-on caregiving [29, 30]. One study found that family caregivers receiving instruction in reflexology can reduce pain and anxiety in cancer patients [31]. Caregiver education for partners is needed to help build their sense of self-efficacy and empower them with the ability to have an impact on patient well-being. Such programs hold the potential to benefit the patient, the partner, and the quality of their relationship [32].

Preliminary to the present study, a phase I feasibility study was conducted using focus groups and experiential workshops to explore attitudes and receptivity toward use of touch in cancer caregiving, and to identify content that could be easily taught and received by lay care partners. That study found inhibitions about touch in cancer lead to unnecessary physical and emotional distancing at a time when patients need touch the most, and that brief instruction could increase caregiver efficacy, patient satisfaction, quality of life, and quality of the relationship [33]. Based upon those findings, a multimedia instructional program was produced to offer psychoeducational content on use of touch and teach simple techniques for comfort and relaxation in cancer caregiving. Multimedia instruction for caregivers (in this study also referred to as "care partners") was seen as a strategy to overcome barriers of cost and access to professionals for touch-based comfort care. This article reports findings of a randomized controlled study that aimed to (1) determine impact of caregiver-administered massages on patient symptoms and side effects, (2) evaluate the effects of the instruction on caregiver attitudes toward use of touch-based methods of supportive care, and (3) assess impact of the intervention on quality of life in patients and stress levels in both patients and caregivers.

\section{Methods}

Instructional materials

Two 6-h workshops were filmed to obtain video footage for an instructional DVD. The workshops were led by WC (principal investigator/clinical social worker), JK and TW (oncology massage practitioners/researchers), and filmed by a professional production company [34]. Eleven adult patient/caregiver dyads consented for filming, including three white, three African American, three Asian American, and two Hispanic/Latino dyads. Relationship diversity included eight spousal couples, one father/daughter, one mother/son, and one sibling pair. The dyads were filmed receiving the instruction, practicing the techniques, and discussing their observations as a group. Spanish and Chinese interpreters assisted. Instructional content included safety precautions related to touch with cancer patients, communication, intention and frame of mind, centering, positioning on home furniture, manual techniques for comfort and relaxation (head, neck, shoulders, back, feet, and hands), and acupressure for pain, anxiety, and nausea.

A 78-min DVD was produced to deliver the instruction outlined above. Expert commentary by an oncologist (David S. Rosenthal, MD) and an oncology nurse researcher (SB) was incorporated in final editing. A language menu offers userselectable voice tracks in English, Spanish, Cantonese, and Mandarin, each with the option of captioning for the hearing impaired. The chapter menu offers user-selectable chapters on the content areas listed above. A 66-page illustrated manual mirrors the DVD content and was produced in English, Spanish, and Chinese versions. The manual includes a "Precautions Checklist" which the user is instructed to review with the patient's physician to identify precautions relevant to the patient's specific medical condition (e.g., pressure restrictions, locations of lymphedema, etc.).

The DVD and manual are bound together and titled Touch, Caring and Cancer: Simple Instruction for Family and Friends. Usability testing on all components was 
conducted during production with a convenience sample of 18 patients and caregivers to obtain recommendations for design and ease of use.

\section{Settings and subjects}

Flyers announcing the opportunity to participate in the project were given by supportive care staff to adult patients and their caregivers at nine cancer treatment centers and support and advocacy organizations in Boston, Massachusetts, Portland, Maine, and Portland, Oregon. Eligibility criteria included age 18 or above; ability to speak, and read and write in English, Spanish, or Chinese; the patient currently experiencing the effects of any type or stage of cancer or its treatments; both patient and caregiver willing to participate; and caregivers with no prior instruction in massage or touch therapy techniques. The application materials included a medical information form and the Precautions Checklist to be completed by the patient's medical provider. The Greater Boston Chinese Golden Age Center and the Latino Health Institute (Boston) assisted with minority recruitment as well as translation and interpreter services. All subjects were consented in person or by phone interview. IRB oversight was provided by the New England Institutional Review Board, Newton, Massachusetts.

\section{Study design}

Subjects were randomized to treatment or control conditions for 4 weeks, after which controls were allowed to join the intervention and all subjects were followed for an additional 16 weeks. (Data on the combined sample's longitudinal use of the intervention will be reported in a separate paper.)

Randomization Block randomization of each dyad was applied based on ethnicity of the patient to achieve equivalent ethnic diversity in treatment and control groups (using http://www.randomization.com). In cases of an odd number of dyads for an ethnicity, a coin flip determined the final dyad's assignment.

Experimental condition Dyads in the experimental condition attended an orientation meeting with other subjects where they viewed the DVD together and were then given a packet containing their own copy of the program plus the data collection materials. No direct instruction or practice took place at the meeting. They were instructed to view the materials (both DVD and manual) as often as they wished and practice techniques of their choice at least three times per week. Suggested duration of sessions was $20 \mathrm{~min}$, but they were told that as little as $5 \mathrm{~min}$ could be beneficial, and they could decide how long each session would last.
Control condition Caregivers assigned to the attention control condition were instructed by phone and written instructions to read to the patient at least three times per week. Suggested duration of sessions was $20 \mathrm{~min}$, but they were told that as little as 5 min could be beneficial, and they could decide how long each session would last. Reading material could be any literature of the patient's choice, such as poetry, fiction, nonfiction, religious, etc.

Data collection All data except medical information, documented by the physician or nurse, were collected via selfreport instruments and submitted through postal mail. Patients and caregivers were asked not to share the answers to the selfreport instruments to avoid interference with the data. All data collection and instructional materials were produced in English, Spanish, and Chinese language versions.

To assess the effects of practice sessions, both groups were instructed to designate one session per week of their assigned activity to use as a "weekly reporting session." This was to be a 20 -min session in which patients rated their symptom levels on a two-sided $5 \times$ 8 -in. card before the session and again $15 \mathrm{~min}$ after. Patients used a 1 to 10 scale to rate how "bothersome" a symptom was, $1=$ "not at all" and $10=$ "extremely." Symptoms assessed included pain, stress/anxiety, depression, fatigue, nausea, and a patient-defined "other" (miscellaneous) symptom. The patient-defined "other" symptom assessment was used to capture less common symptoms yet those that were significant to patients. This approach and the use of session cards was successfully used in a prior study of massage session effects by Cassileth and Vickers [19]. At the same weekly reporting session the care partner completed a card reporting the duration of the reporting session, total number of sessions conducted during the past week, average duration, and, for experimental dyads, viewings of the instructional materials.

In addition to the weekly reports, a survey package was completed at baseline and 4-week follow-up. Caregivers completed seven investigator-generated questions on attitudes toward caregiving (Table 5), all rated from 1, "lowest" to 10 , "highest." They also completed the seven-item caregiver esteem subscale of the Caregiver Reaction Assessment [35], one of seven subscales derived using confirmatory factor analysis on an independent sample $(N=377)$ and tested for factorial invariance across spouse and nonspouse caregivers of persons with cancer or Alzheimer's disease. Responses range from 1, "strongly disagree" to 5, "strongly agree."

Both caregiver and patient completed the Perceived Stress Scale (PSS-10), a 10-item Likert-scaled instrument with responses ranging from 0 , "never" to 4 , "very often," to determine perceived stress levels over a one-month recall 
period. The PSS is a validated and widely used scale for community samples with at least a junior high school education [36].

Patients also completed the Functional Assessment of Cancer Therapy-General (FACT-G, version 4) [37]. This is a validated, widely used instrument with 27 Likert-scaled items (0-4) yielding a total score and subscale scores for physical, functional, social/family, and emotional adjustment. The scale has been shown to discriminate patients based on stage of disease, performance status, and hospitalization status.

Safety monitoring For dyads using massage, one home visit was conducted at the beginning of the intervention period by an oncology massage therapist. The purpose was to observe for proper implementation of safety precautions specific to the patient as identified on the precautions checklist completed by the patient's medical practitioner. Assessment for adverse events was conducted by phone query by the research assistant bi-weekly.
Statistical methods

Categorical demographic data were compared using either Chi-square tests or Fisher's exact $p$. Continuous data were compared using $t$ tests.

To determine effects of massage and reading sessions on symptoms, mean pre- and postsession ratings were calculated for each symptom for each of the four weekly reporting sessions. Next, weighted group means across the four reporting sessions were calculated to determine mean "difference scores" and percent change for each symptom.

Group-by-time repeated measures analysis of variance (ANOVA) was used to assess group differences in changes over time. This method was applied both to session effects on symptoms, and to the survey data collected at baseline and 4-week follow-up.

Finally, hierarchically optimal classification tree analysis (CTA) [38] was conducted to search for predictors of individual responses to the follow-up survey

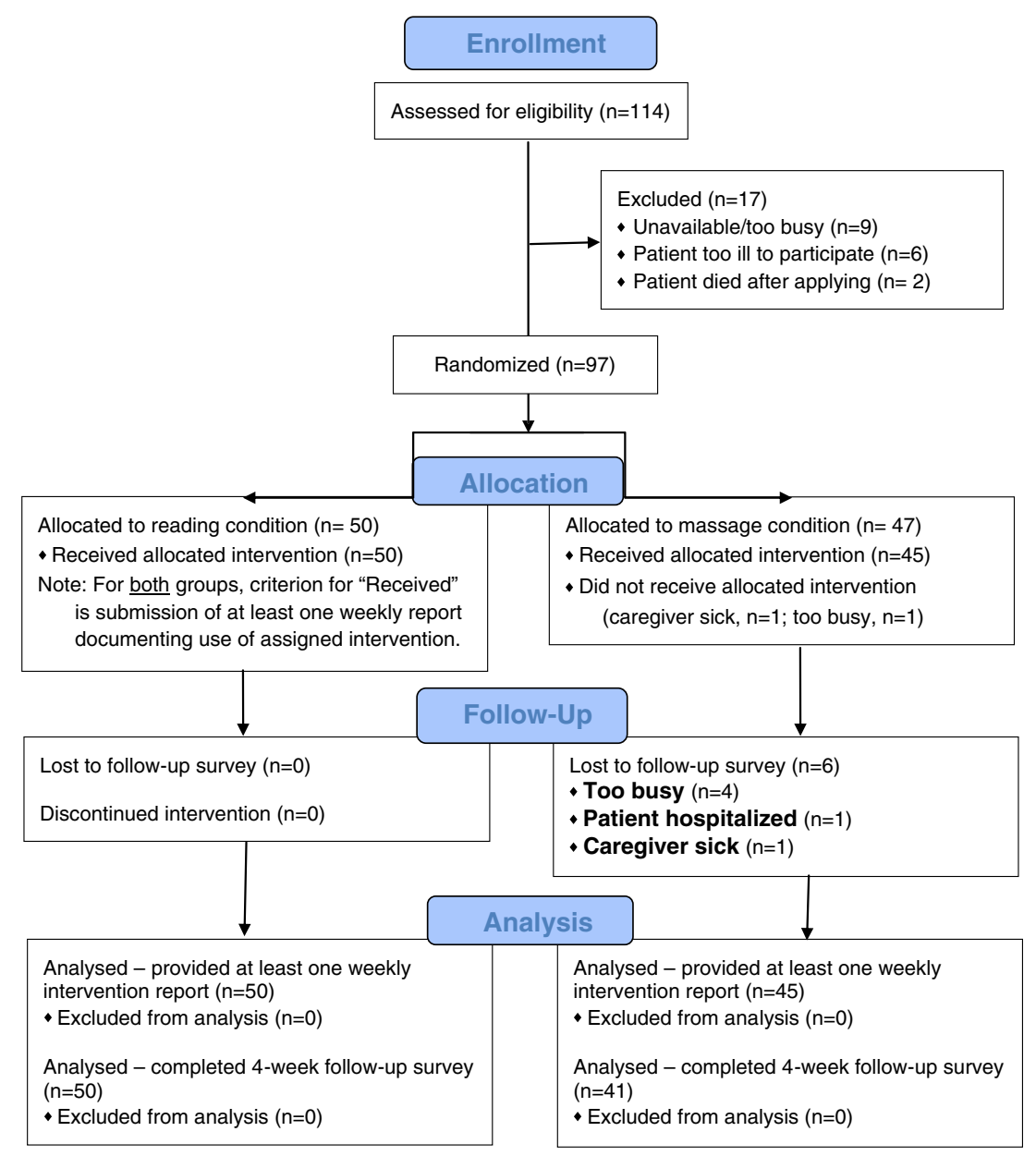

Fig. 1 CONSORT flow diagram 
Table 1 Sample

\begin{tabular}{|c|c|c|}
\hline Demographics & Patients & Caregivers \\
\hline \multicolumn{3}{|l|}{$\operatorname{Sex}(\%(n))$} \\
\hline Male & $23.7(23)$ & $44.3(43)$ \\
\hline Female & $76.3(74)$ & $55.7(54)$ \\
\hline \multicolumn{3}{|l|}{ Age (years) } \\
\hline Mean (SD) & $54.7(11.6)$ & $51.5(13.6)$ \\
\hline Median & 56.0 & 53.0 \\
\hline Range & $24-78$ & $18-82$ \\
\hline Ethnicity (\% (n) White) & $65.0(63)$ & $66.0(64)$ \\
\hline African American & $13.4(13)$ & $13.4(13)$ \\
\hline Asian & $12.4(12)$ & $10.3(10)$ \\
\hline Hispanic & $8.2(8)$ & $8.2(8)$ \\
\hline Native American & $1.0(1)$ & $2.1(2)$ \\
\hline \multicolumn{3}{|l|}{ Education $(\%(n))$} \\
\hline No high school & $1.0(1)$ & $2.1(2)$ \\
\hline Some high school & $0.0(0)$ & $2.1(2)$ \\
\hline High school graduate & $14.4(14)$ & $17.5(17)$ \\
\hline Some college & $5.2(5)$ & $17.5(17)$ \\
\hline College graduate & $59.8(58)$ & $40.2(39)$ \\
\hline Graduate degree & $18.6(18)$ & $18.6(18)$ \\
\hline Unknown & $1.0(1)$ & $2.1(2)$ \\
\hline \multicolumn{3}{|l|}{ Caregiver relationship to patient $(\%(n))$} \\
\hline Spouse or life partner & $64(62)$ & \\
\hline Adult child & $17.5(17)$ & \\
\hline Parent & $4.2(4)$ & \\
\hline Friend & $10.3(11)$ & \\
\hline Other relative & $3(3)$ & \\
\hline \multicolumn{3}{|l|}{ Share household (77 (75)) } \\
\hline Duration of relationship ((years) mean (SD)) & $25.5(14.8)$ & \\
\hline Median (range) & $24.3(1-62)$ & \\
\hline \multicolumn{3}{|l|}{ Patient cancer history at enrollment ${ }^{\mathrm{a}}$} \\
\hline Months since diagnosis (mean (SD)) & $29.7(40.2)$ & \\
\hline Median (range) & $12(1$ to 258$)$ & \\
\hline \multicolumn{3}{|l|}{ Stage $(\%(n))$} \\
\hline I & $9.3(9)$ & \\
\hline II & $24.7(24)$ & \\
\hline III & $16.5(16)$ & \\
\hline IV & $36.1(35)$ & \\
\hline Remission & $5.2(5)$ & \\
\hline Unknown & $8.2(8)$ & \\
\hline Metastasis & $41.2(40)$ & \\
\hline \multicolumn{3}{|l|}{ Treatment $(\%(n))$} \\
\hline Chemotherapy & $66.0(64)$ & \\
\hline Radiation & $48.4(47)$ & \\
\hline Surgery & $79.4(77)$ & \\
\hline
\end{tabular}

${ }^{\mathrm{a}}$ Information provided by physician or nurse

outcomes. All demographic variables and utilization variables (i.e., frequency and duration of the use of the interventions) were entered as potential predictors of survey outcomes. 


\section{Results}

Sample

A total of 114 dyads applied to participate in the study. Seventeen were excluded because of being unavailable, the patient too ill, or the patient died during the enrollment process, and 97 were randomized (see Fig. 1). Demographic variables and patient diagnostic and treatment status are shown in Table 1. The majority of dyads were in a spouse or partner relationship sharing the same household. We used Fisher's exact tests to compare the two groups on demographic, stage, and treatment variables and found no significant differences between groups.

Languages Eight dyads were Spanish speaking, with the four experimental dyads using the Spanish language program. Ten dyads were Chinese speaking, with the five experimental dyads using the Chinese language program. All others used the English language program.

Diagnoses Types of cancer represented were breast $(n=44)$, lung $(n=10)$, gastrointestinal $(n=10)$, blood $(n=9)$, gynecological $(n=8)$, brain $(n=4)$, prostate $(n=3)$, thyroid $(n=3)$, kidney $(n=2)$, and one each of melanoma, peritoneal, testicular, and tongue. Over half of patients were stage III or IV at enrollment, and all had received conventional treatment (Table 1).

\section{Attrition}

As seen in Fig. 1, all attrition was from the experimental condition. Two dyads dropped out before starting intervention, two dropped during the intervention period, and two completed intervention (with four weekly reports) but not the follow-up survey (see Fig. 1 for reasons).

Table 2 Reported activity over 4 weeks

\begin{tabular}{lc}
\hline Group & Mean (SD) \\
\hline Massage ( $N=45$ dyads) & \\
Times viewed DVD weekly & $1.35(2.03)$ \\
Times viewed manual weekly & $1.64(1.36)$ \\
Number of massages weekly & $3.60(4.05)$ \\
Duration each massage (minutes) & $17.80(11.86)$ \\
Reading ( $N=50$ dyads) & \\
Number of reading sessions weekly & $3.79(3.39)$ \\
Duration each reading (minutes) & $22.50(13.63)$ \\
\hline
\end{tabular}

Caregiver outcomes

Utilization Caregiver compliance with weekly assigned activities was high in both groups with no significant differences in average frequency or duration of sessions. Massage caregivers reported accessing the instructional materials about three times per week (Table 2).

Caregiver attitudes Both groups of caregivers had significant increases over the 4 weeks in satisfaction with their ability to help the patient feel better and reduced concern about causing distress with touch (Table 3 ). In addition there were significant time by group effects, with massage caregivers becoming more comfortable using touch and massage, and increasing perceived self-efficacy in providing massage (comfort providing massage and confident can provide massage effectively).

Stress and caregiver esteem There were no significant within- or between-group differences for caregivers on the PSS-10 or the Caregiver Esteem Scale.

\section{Patient outcomes}

Session effects on symptoms Both groups reported significantly reduced postsession scores for all symptoms $(p<0.001$ for all proportions of change for both conditions) (Table 4). Reductions for reading patients averaged $12 \%$ (for nausea) to $28 \%$ (for stress/anxiety) while massage patients averaged $29 \%$ (for nausea) to $44 \%$ (for stress/anxiety).

The average proportion of decreased symptomatology reported from pre- to postsessions over the 4 weeks was significantly greater for patients in the massage condition for three of the symptoms: pain (34 vs. $18 \%, p=0.04$ ), nausea (29 vs. $12 \%, p=0.02)$, and other self-reported symptoms (42 vs. $17 \%, p=0.02$ ) (Table 4 ).

Comparison of session effects for the two groups across time (Table 5) found reductions in symptom ratings to be significantly greater for massage than reading, as follows: for stress/anxiety in weeks 2, 3, and 4; for pain in weeks 3 and 4; and for fatigue in weeks 1 and 4. ANOVA results showed significant group effects for stress/anxiety $\left(F_{(1,78)}=\right.$ 8.82, $p=0.004)$, pain $\left(F_{(1,79)}=4.41, p=0.04\right)$, and fatigue $\left(F_{(1,78)}=6.26, p=0.01\right)$, with no significant effects for time or group by time.

Stress and quality of life There were no significant withinor between-group differences for patients on the PSS-10 or the FACT-G. However, CTA, which was applied to all patient survey outcomes, found a statistically significant model associating patients' diagnostic and massage variables with their PSS-10 score at follow-up (Fig. 2). In the model, $81.2 \%$ of patients diagnosed with stage I-III cancer improved their PSS-10 score regardless of any other 
Table 3 Change in caregiver attitudes from baseline to 4-week follow-up

\begin{tabular}{|c|c|c|c|c|c|c|c|c|c|c|}
\hline \multirow[t]{2}{*}{ Question } & \multicolumn{2}{|c|}{$\begin{array}{l}\text { Baseline mean } \\
\text { (SD) }\end{array}$} & \multicolumn{2}{|c|}{$\begin{array}{l}\text { Follow-up mean } \\
\text { (SD) }\end{array}$} & \multirow[t]{2}{*}{ Time } & \multirow[t]{2}{*}{$p$} & \multirow[t]{2}{*}{ Time by group } & \multirow[t]{2}{*}{$p$} & \multirow[t]{2}{*}{$\begin{array}{l}\text { Group } \\
\text { difference }\end{array}$} & \multirow[t]{2}{*}{$p$} \\
\hline & Massage & Reading & Massage & Reading & & & & & & \\
\hline $\begin{array}{l}\text { 1. In general, how satisfied are } \\
\text { you today with your ability to } \\
\text { help your partner feel better? }\end{array}$ & $\begin{array}{l}7.36 \\
(2.22)\end{array}$ & $\begin{array}{l}7.31 \\
(2.07)\end{array}$ & $\begin{array}{l}7.93 \\
\quad(1.98)\end{array}$ & $\begin{array}{l}7.67 \\
(1.83)\end{array}$ & $F_{(1,85)}=5.536$ & 0.02 & $F_{(1,85)}=0.300$ & 0.58 & $F_{(1,85)}=0.158$ & 0.69 \\
\hline $\begin{array}{l}\text { 2. How comfortable are you today } \\
\text { with using touch as a form of } \\
\text { support for your partner? }\end{array}$ & $\begin{array}{l}8.12 \\
(2.43)\end{array}$ & $\begin{array}{l}8.49 \\
(2.16)\end{array}$ & $\begin{array}{l}8.64 \\
(1.94)\end{array}$ & $\begin{array}{l}8.04 \\
(2.41)\end{array}$ & $F_{(1,85)}=0.029$ & 0.87 & $F_{(1,85)}=4.268$ & 0.04 & $F_{(1,85)}=0.073$ & 0.78 \\
\hline $\begin{array}{l}\text { 3. How concerned are you today } \\
\text { about causing pain or discomfort } \\
\text { by touching your partner? }\end{array}$ & $\begin{array}{l}4.74 \\
(3.13)\end{array}$ & $\begin{array}{l}5.13 \\
\quad(3.08)\end{array}$ & $\begin{array}{l}3.31 \\
\quad(2.77)\end{array}$ & $\begin{array}{l}4.84 \\
\quad(3.10)\end{array}$ & $F_{(1,85)}=7.345$ & 0.008 & $F_{(1,85)}=3.324$ & 0.08 & $F_{(1,85}=2.897$ & 0.09 \\
\hline $\begin{array}{l}\text { 4. How concerned are you today } \\
\text { about touch making your } \\
\text { partner's medical condition } \\
\text { worse? }\end{array}$ & $\begin{array}{l}3.29 \\
(3.18)\end{array}$ & $\begin{array}{l}3.73 \\
(3.32)\end{array}$ & $\begin{array}{l}2.29 \\
(2.40)\end{array}$ & $\begin{array}{l}3.71 \\
(3.03)\end{array}$ & $F_{(1,85)}=3.276$ & 0.07 & $F_{(1,85)}=2.997$ & 0.09 & $F(1,85)=2.598$ & 0.11 \\
\hline $\begin{array}{l}\text { 5. How comfortable are you } \\
\text { today in talking with your } \\
\text { partner about touch? }\end{array}$ & $\begin{array}{l}8.40 \\
(2.61)\end{array}$ & $\begin{array}{l}8.67 \\
(1.71)\end{array}$ & $\begin{array}{l}9.00 \\
(1.59)\end{array}$ & $\begin{array}{l}8.33 \\
(2.28)\end{array}$ & $F_{(1,85)}=0.274$ & 0.60 & $F_{(1,85)}=3.445$ & 0.07 & $F_{(1,85)}=0.297$ & 0.59 \\
\hline $\begin{array}{l}\text { 6. How comfortable are you } \\
\text { today with providing any form } \\
\text { of massage to your partner? }\end{array}$ & $\begin{array}{l}8.10 \\
(2.55)\end{array}$ & $\begin{array}{l}8.80 \\
(1.50)\end{array}$ & $\begin{array}{l}8.55 \\
(1.93)\end{array}$ & $\begin{array}{l}8.11 \\
(2.43)\end{array}$ & $F_{(1,85)}=0.279$ & 0.60 & $F_{(1,85)}=6.499$ & 0.01 & $F_{(1,85)}=0.112$ & 0.74 \\
\hline $\begin{array}{l}\text { 7. How confident are you today } \\
\text { that you can provide massage } \\
\text { effectively as a form of support to } \\
\text { your partner? }\end{array}$ & $\begin{array}{l}7.38 \\
(2.82)\end{array}$ & $\begin{array}{l}8.00 \\
\quad(2.11)\end{array}$ & $\begin{array}{l}8.29 \\
(2.27)\end{array}$ & $\begin{array}{l}7.71 \\
(2.35)\end{array}$ & $F_{(1,85)}=1.206$ & 0.28 & $F_{(1,85)}=4.529$ & 0.04 & $F_{(1,85)}=0.003$ & 0.96 \\
\hline
\end{tabular}

variables, including group assignment $(p=0.045)$. For stage IV patients, however, improvement on the PSS-10 was predicted by their reported mean duration of massage sessions received: only $15.4 \%$ of patients reporting a mean of $<13.75 \mathrm{~min} /$ session improved, while $78.3 \%$ of those with a mean of $\geq 13.75$ min improved ( $p=0.0001)$. This model had an effect strength for sensitivity of 45.6 , a moderate effect
[39]. No other classification trees were produced by the data.

\section{Adverse events}

There were no reports of adverse events related to participation during the study period.

Table 4 Session effects: weighted means (SD) of 4 weeks of symptom ratings pre- and postsession

\begin{tabular}{|c|c|c|c|c|c|}
\hline Symptom & Group & Pre & Post & $\%$ change $^{a}$ & $\begin{array}{l}\text { Test of difference in } \% \\
\text { change between groups }\end{array}$ \\
\hline Stress/anxiety & $\begin{array}{l}\text { Reading } \\
\text { Massage }\end{array}$ & $\begin{array}{l}4.75(2.63) \\
4.86(2.52)\end{array}$ & $\begin{array}{l}3.43(2.21) \\
2.72(1.59)\end{array}$ & $\begin{array}{l}28 \\
44\end{array}$ & 0.06 \\
\hline Pain & $\begin{array}{l}\text { Reading } \\
\text { Massage }\end{array}$ & $\begin{array}{l}4.23(2.66) \\
3.97(2.66)\end{array}$ & $\begin{array}{l}3.46(2.46) \\
2.62(1.92)\end{array}$ & $\begin{array}{l}18 \\
34\end{array}$ & 0.04 \\
\hline Fatigue & $\begin{array}{l}\text { Reading } \\
\text { Massage }\end{array}$ & $\begin{array}{l}5.46(2.39) \\
5.44(2.00)\end{array}$ & $\begin{array}{l}4.37(2.26) \\
3.70(2.15)\end{array}$ & $\begin{array}{l}20 \\
32\end{array}$ & 0.10 \\
\hline Depression & $\begin{array}{l}\text { Reading } \\
\text { Massage }\end{array}$ & $\begin{array}{l}3.24(2.18) \\
3.13(2.38)\end{array}$ & $\begin{array}{l}2.52(1.85) \\
2.17(1.62)\end{array}$ & $\begin{array}{l}22 \\
31\end{array}$ & 0.17 \\
\hline Nausea & $\begin{array}{l}\text { Reading } \\
\text { Massage }\end{array}$ & $\begin{array}{l}2.08(2.12) \\
2.01(2.08)\end{array}$ & $\begin{array}{l}1.83(1.83) \\
1.42(1.42)\end{array}$ & $\begin{array}{l}12 \\
29\end{array}$ & 0.02 \\
\hline Other & $\begin{array}{l}\text { Reading } \\
\text { Massage }\end{array}$ & $\begin{array}{l}4.37(3.01) \\
2.53(2.96)\end{array}$ & $\begin{array}{l}3.62(2.74) \\
1.47(2.48)\end{array}$ & $\begin{array}{l}17 \\
42\end{array}$ & 0.02 \\
\hline
\end{tabular}

Weighted group means and standard deviations across four weekly "reporting sessions" per group

${ }^{\mathrm{a}}$ Test of proportion, $>0 \%$;

$p<0.001$ for all proportions in both conditions 
Table 5 Pre- to postsession change in symptom ratings over the four weekly reporting sessions: repeated measures ANOVA results

\begin{tabular}{|c|c|c|c|c|c|c|c|c|}
\hline & \multicolumn{8}{|c|}{ Mean (SD) reduction in symptom ratings by week group } \\
\hline & \multicolumn{2}{|l|}{ Week 1} & \multicolumn{2}{|l|}{ Week 2} & \multicolumn{2}{|l|}{ Week 3} & \multicolumn{2}{|l|}{ Week 4} \\
\hline & Massage & Reading & Massage & Reading & Massage & Reading & Massage & Reading \\
\hline \multirow[t]{2}{*}{ Stress/anxiety } & $2.03(1.84)$ & $1.46(1.57)$ & $2.13(1.87)$ & $0.93(1.84)$ & $2.15(2.07)$ & $1.29(1.15)$ & $2.08(1.80)$ & $1.22(1.48)$ \\
\hline & $t(78)=1.47$ & & $t(78)=2.90 * *$ & & $t(58.61)=2.2$ & & $t(78)=2.34^{*}$ & \\
\hline \multirow[t]{2}{*}{ Pain } & $1.25(1.53)$ & $0.95(1.41)$ & $1.20(1.34)$ & $0.85(1.67)$ & $1.425(1.62)$ & $0.78(1.26)$ & $1.375(1.44)$ & $0.59(1.18)$ \\
\hline & $t(79)=0.91$ & & $t(79)=1.03$ & & $t(79)=2.01 *$ & & $t(79)=2.70^{* *}$ & \\
\hline \multirow[t]{2}{*}{ Fatigue } & $1.90(1.53)$ & $1.075(1.40)$ & $1.875(1.51)$ & $1.30(1.70)$ & $1.40(1.57)$ & $1.125(1.44)$ & $1.80(1.88)$ & $0.85(1.51)$ \\
\hline & $t(78)=2.51^{* *}$ & & $t(78)=1.60$ & & $t(78)=0.82$ & & $t(78)=2.49^{*}$ & \\
\hline \multirow[t]{2}{*}{ Depression } & $0.92(1.17)$ & $0.65(1.03)$ & $1.13(1.80)$ & $0.45(1.89)$ & $0.82(1.11)$ & $0.775(1.33)$ & $1.00(1.51)$ & $0.725(1.09)$ \\
\hline & $t(76)=1.09$ & & $t(76)=1.63$ & & $t(76)=0.15$ & & $t(76)=0.93$ & \\
\hline \multirow[t]{2}{*}{ Nausea } & $0.51(0.82)$ & $0.39(1.07)$ & $0.74(1.50)$ & $0.32(1.15)$ & $0.44(0.94)$ & $0.17(0.63)$ & $0.62(0.94)$ & $0.32(0.96)$ \\
\hline & $t(74.80)=0.58$ & & $t(78)=1.43$ & & $t(68.87)=1.4$ & & $t(78)=1.41$ & \\
\hline \multirow[t]{2}{*}{ Other } & $1.07(1.74)$ & $1.00(1.35)$ & $1.37(2.06)$ & $2.08(5.38)$ & $0.53(1.38)$ & $0.75(1.06)$ & $1.33(2.22)$ & $0.58(1.16)$ \\
\hline & $t(74.80)=0.58$ & & $t(78)=-1.43$ & & $t(68.87)=-1$ & & $t(78)=1.41$ & \\
\hline
\end{tabular}

$* p<0.05 ; * * p<0.01 ; * * * p<0.001$

\section{Discussion}

An interesting comparison can be made between the massage effects obtained by the care partners in this study and those of professional massage therapists documented in other studies. For example, while there was slight difference in symptom scales between this and the Cassileth and Vickers study [19] (10 vs. 11 scale points), the magnitude of symptom reductions reported in this study (29-44\%) approached that of professionals (21-52\%) - equaling them for depression (31\%) and surpassing them for nausea ( 29 vs. $21 \%$ ).

An obvious consideration is the nature of the relationship between provider and recipient. Clearly the relationship dynamics with a care partner at home are very different from those with a professional. Use of massage in the context of an established and ongoing intimate relationship introduces the possibility of additional psychosocial

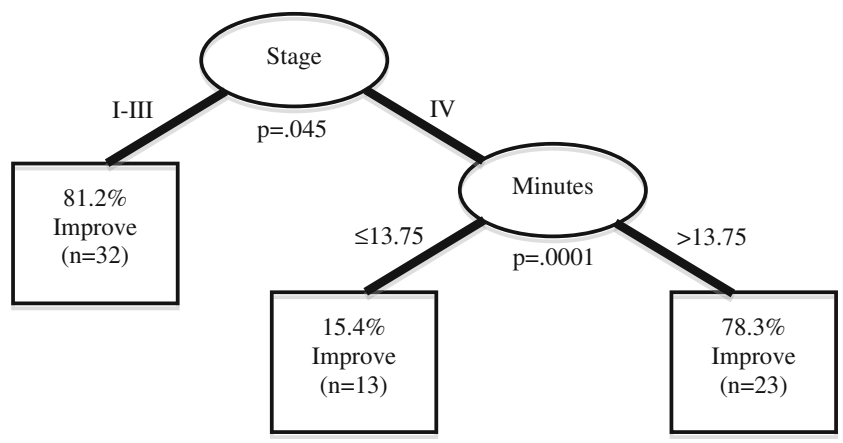

Fig. 2 CTA model: cancer stage and reported duration of massage sessions predict improvement in PSS-10 at follow-up variables that may affect outcomes. This may help explain, for example, the observed reductions in depression and nausea that compare favorably with those of professionals. Future research could elucidate what qualities of the caregiving relationship may enhance or impede the impact of this form of support on symptoms, and may point to new relationship interventions for enhancing outcomes.

We note that all attrition (six dyads) was in the massage group. We attempted to match subject burden between the two groups in terms of time demanded by the study. The fact that two of these six dyads completed all 4 weeks of intervention but missed only the follow-up survey suggests the nature of the intervention was not an obstacle for them. For the other four dyads, illness in the caregiver or patient was reported by two while "too busy" was reported by the other two. We cannot rule out the nature of the intervention as a contributing factor for these four. It seems plausible that use of massage may be perceived as more taxing than the reading activity for caregivers who may already be feeling burdened. This may point to the value of offering added support or encouragement to users of the massage instruction as opposed to presenting it as the completely autonomous and self-directed approach used in this study.

The fact that the reading companionship led to significant reductions in symptoms, though not to the extent of massage, underscores the impact of attention as a potent force that needs to be controlled for in future studies of caregiver intervention. It also suggests that very simple practices such as reading or other structured attention activities might be worthy of further clinical investigation as deliberate interventions in themselves. 
The reasons for lack of significant changes on the PSS-10, as well as the FACT-G for patients, are unclear. It may be that the intervention was not sufficiently powerful to impact those measures, that the measures were not sensitive enough, that there were ceiling effects, or that more time is needed for effects to arise. We aim to learn more from a later analysis of longitudinal (16 weeks post-RCT) data from the combined sample.

The CTA model for stage IV patients, indicating a doseresponse relationship between duration of massage sessions and stress scores at follow-up, is intriguing. It may be that a longer session allows more opportunity for relaxation effects as well as a deepened sense of connection and intimacy with the giver. These factors separately or combined may contribute to declining background stress over time. A formal dose-response study with a larger sample of stage IV dyads may potentially yield new guidelines for enhanced caregiving with these patients.

As for caregiver esteem, in examining the caregiver attitude scores it is clear that caregivers came into the study with a relatively high degree of confidence in their abilities to provide care, which may have influenced their choice to enroll. Thus a ceiling effect may account for the lack of significant increase in caregiver esteem.

The safety monitoring in home visits appeared to confirm that multimedia instruction regarding safety precautions was effective, and that a focus on the broad concept of "comfort and relaxation" rather than "treatment" or "massage therapy" per se enables users to apply the instruction without undue inhibition. This is important because a common concern around use of massage and touch methods by family members in cancer is the possibility of adverse effects.

During the course of the study we received many anecdotal reports in the form of freehand comments on subjects' weekly report cards, verbal statements to the research assistant during phone communications, and comments made to the oncology massage therapists during observation visits. We did not conduct a systematic approach to collection or analysis of qualitative data. We can only report informally that many positive comments were made about the impact of both the massage and reading activities on the quality of the relationship, particularly in reference to the theme of spending "quality time" together. Future research on this form of intervention should build in a structured approach to collection and analysis of qualitative data pertaining to quality of relationship.

Since professionals' effects were found to last up to $48 \mathrm{~h}$ in the Cassileth and Vickers study, this raises an intriguing question: could patients receiving multiple sessions per week from a care partner at home experience sustained symptom reduction, and therefore improved quality of life, on-going with this form of support?

To answer this question would require study of the shortand longer-term duration of effects by care partners. If found to be the case, this could have important implications for caregiver education initiatives - especially for low-income and underserved populations who are less likely to have access to supportive and palliative care resources. For example, educational initiatives could disseminate this form of instruction via workshops, support groups, community presentations, in-house video networks, or orientation materials given to families entering a cancer care environment.

An important limitation of this study is the heterogeneity of the sample. Randomization was based solely on ethnicity, with no matching by type or stage of cancer, relationship type, or other subject variables, as the focus of the research was on the broader themes of caregiving and patients' acute responses to practice sessions. Hence, while analysis of demographic data found no differences between groups, clinical equivalence of the groups was not assured.

In summary, this study suggests that multimedia instruction in simple massage and touch-based methods of supportive care at home may offer family members a viable means of enhancing self-efficacy and satisfaction in caregiving. Family members can learn and safely apply uncomplicated methods that increase patient comfort and reduce distress. Currently, the program is being used in cancer centers, hospices, and other palliative care settings in the USA, Canada, UK, Ireland, Australia, and Vietnam, with the language options facilitating outreach to underserved populations. Further research is needed to explore effects in more narrowly conscribed samples and diverse methods of dissemination including internet download.

Acknowledgments The authors wish to thank the patients and caregivers who made this study possible, as well as the following collaborating organizations: Latino Health Institute, Greater Boston Chinese Golden Age Center, Wellness Community of Greater Boston, Harvard Cooperative Program on Aging, and Caritas Carney Hospital Social Work Department, all in Boston; Portsmouth Regional Hospital Oncology Clinic, Portsmouth, NH; Center for Cancer Care, Exeter, NH; Cancer Community Center, South Portland, ME; Providence Cancer Center, Portland, OR; and CrossCurrent Communications, Portsmouth, $\mathrm{NH}$.

Conflict of interest William Collinge is president and owner of Collinge and Associates which was funded by NCI to conduct the research and produce the Touch, Caring, and Cancer program for dissemination to the public. Dr. Collinge has full control of all primary data and agrees to allow the journal to view data if requested.

Funding This project was funded by grant No. R44CA103606-3, Multimedia Technology Health Communication SBIR/STTR Grants, Health Communication Informatics Research Branch, Behavioral Research Program, Division of Cancer Control and Population Sciences, National Cancer Institute, National Institutes of Health, USA.

Open Access This article is distributed under the terms of the Creative Commons Attribution Noncommercial License which permits any noncommercial use, distribution, and reproduction in any medium, provided the original author(s) and the source are credited. 


\section{References}

1. Listing M, Krohn M, Liezmann C, Kim I, Reisshauer A, Peters E, Klapp BF, Rauchfuss M (2010) The efficacy of classical massage on stress perception and cortisol following primary treatment of breast cancer. Arch Womens Ment Health 13(2):165-173

2. Stringer J, Swindell R, Dennis M (2008) Massage in patients undergoing intensive chemotherapy reduces serum cortisol and prolactin. Psychooncology 17(10):1024-1031

3. Sharp DM, Walker MB, Chaturvedi A, Upadhyay S, Hamid A, Walker AA, Bateman JS, Braid F, Ellwood K, Hebblewhite C, Hope T, Lines M, Walker LG (2010) A randomised, controlled trial of the psychological effects of reflexology in early breast cancer. Eur J Cancer 46(2):312-322

4. Sturgeon M, Wetta-Hall R, Hart T, Good M, Dakhil S (2009) Effects of therapeutic massage on the quality of life among patients with breast cancer during treatment. J Altern Complement Med 15 (4):373-380

5. Billhult A, Stener-Victorin E, Bergbom I (2007) The experience of massage during chemotherapy treatment in breast cancer patients. Clin Nurs Res 16(2):85-99

6. Wilkie DJ, Kampbell J, Cutshall S, Halabisky H, Harmon H, Johnson LP, Weinacht L, Rake-Marona M (2000) Effects of massage on pain intensity, analgesics and quality of life in patients with cancer pain: a pilot study of a randomized clinical trial conducted within hospice care delivery. Hosp J 15(3):31-53

7. Listing M, Reisshauer A, Krohn M, Voigt B, Tjahono G, Becker J, Klapp BF, Rauchfuss M (2009) Massage therapy reduces physical discomfort and improves mood disturbances in women with breast cancer. Psychooncology 18(12):1290-1299

8. Campeau MP, Gaboriault R, Drapeau M, Van Nguyen T, Roy I, Fortin B, Marois M, Nguyen-Tân PF (2007) Impact of massage therapy on anxiety levels in patients undergoing radiation therapy: randomized controlled trial. J Soc Integr Oncol 5(4):133-138

9. Mehling WE, Jacobs B, Acree M, Wilson L, Bostrom A, West J, Acquah J, Burns B, Chapman J, Hecht FM (2007) Symptom management with massage and acupuncture in postoperative cancer patients: a randomized controlled trial. J Pain Symptom Manage 33(3):258-266

10. Billhult A, Bergbom I, Stener-Victorin E (2007) Massage relieves nausea in women with breast cancer who are undergoing chemotherapy. J Altern Complement Med 13(1):53-57

11. Post-White J, Kinney ME, Savik K, Gau JB, Wilcox C, Lerner I (2003) Therapeutic massage and healing touch improve symptoms in cancer. Integr Cancer Ther 2(4):332-344

12. Stephenson N, Dalton JA, Carlson J (2003) The effect of foot reflexology on pain in patients with metastatic cancer. Appl Nurs Res 16(4):284-286

13. Weinrich SP, Weinrich MC (1990) The effect of massage on pain in cancer patients. Appl Nurs Res 3(4):140-145

14. Smith MC, Kemp J, Hemphill L, Vojir CP (2002) Outcomes of therapeutic massage for hospitalized cancer patients. J Nurs Scholarsh 34(3):257-262

15. Ross CS, Hamilton J, Macrae G, Docherty C, Gould A, Cornbleet MA (2002) A pilot study to evaluate the effect of reflexology on mood and symptom rating of advanced cancer patients. Palliat Med 16(6):544-545

16. Grealish L, Lomasney A, Whiteman B (2000) Foot massage: a nursing intervention to modify the distressing symptoms of pain and nausea in patients hospitalized with cancer. Cancer Nurs 23(3):237-243

17. Stephenson NL, Weinrich SP, Tavakoli AS (2000) The effects of foot reflexology on anxiety and pain in patients with breast and lung cancer. Oncol Nurs Forum 27(1):67-72

18. Kutner JS, Smith MC, Corbin L, Hemphill L, Benton K, Mellis BK, Beaty B, Felton S, Yamashita TE, Bryant LL, Fairclough DL
(2008) Massage therapy versus simple touch to improve pain and mood in patients with advanced cancer: a randomized trial. Ann Intern Med 149(6):369-379

19. Cassileth BR, Vickers AJ (2004) Massage therapy for symptom control: outcome study at a major cancer center. J Pain Sympt Management 28(3):244-249

20. Demmer C (2004) A survey of complementary therapy services provided by hospices. J Palliat Med 7(4):510-516

21. Kozak LE, Kayes L, McCarty R, Walkinshaw C, Congdon S, Kleinberger J, Hartman V, Standish LJ (2009) Use of complementary and alternative medicine (CAM) by Washington State hospices. Am J Hosp Palliat Care 25(6):463-468

22. Wellisch DK, Jamison KR, Passau RO (1978) Psychosocial aspects of mastectomy: II. The man's perspective. Am J Psychiatry 135:543-546

23. Keller M, Henrich G, Beutel M, Sellschopp A (1998) Mutuality of distress and support in couples including a cancer patient. Psychother Psychosom Med Psyc 48(9-10):358-368

24. Omne-Ponte M, Homnber L, Bergstron R, Sjoden PO, Burns T (1993) Psychosocial adjustment among husbands of women treated for breast cancer: mastectomy versus breast conserving surgery. Eur J Cancer 29A:1393-1397

25. Northouse LL, Mood D, Templin T, Mellon S, George T (2000) Couples' patterns of adjustment to colon cancer. Soc Sci Med 50 (2):271-284

26. Baider L, DeNour A (1984) Couples' reactions and adjustment to mastectomy: a preliminary report. Int J Psychiatry Med 14:265276

27. Baider L, Kaplan De-Nour A (1988) Adjustment to cancer: who is the patient — the husband or the wife? Isr J Med Sci 24(9-10):631636

28. Kirschner-Hermanns R, Jakse G (2002) Quality of life following radical prostatectomy. Crit Rev Oncol Hematol 43(2):141

29. Poulin MJ, Brown SL, Ubel PA, Smith DM, Jankovic A, Langa KM (2010) Does a helping hand mean a heavy heart? Helping behavior and well-being among spouse caregivers. Psychol Aging 25(1):108-117

30. Field T, Hernandez-Reif M, Quintino O, Wheeden C, Schanberg S, Kuhn C (1997) Elder retired volunteers benefit from giving massage therapy to infants. J Appl Gerontol 17:229-239

31. Stephenson NL, Swanson M, Dalton J, Keefe FJ, Engelke M (2007) Partner-delivered reflexology: effects on cancer pain and anxiety. Oncol Nurs Forum 34(1):127-132

32. McCorkle R, Pasacreta J (2001) Enhancing caregiver outcomes in palliative care. Cancer Control 8(1):36-45

33. Collinge W, Kahn J, Yarnold P, Bauer-Wu S, McCorkle R (2007) Couples and cancer: feasibility of brief instruction in massage and touch therapy to build caregiver efficacy. J Soc Integr Oncol 5 (4):147-154

34. CrossCurrent Communications (2012) CrossCurrent Productions, Portsmouth, New Hampshire

35. Given CW, Given B, Stommel M, Collins C, King S, Franklin S (1992) The caregiver reaction assessment (CRA) for caregivers to persons with chronic physical and mental impairments. Res Nurs Health 15(4):271-283

36. Cohen S, Kamarck T, Mermelstein R (1983) A global measure of perceived stress. J Health Soc Behav 24:385-396

37. Cella DF, Tulsky DS, Gray G (1993) The Functional Assessment of Cancer Therapy Scale: development and validation of the general measure. J Clin Oncol 11(3):570-579

38. Yarnold PR, Soltysik RC, Bennett CL (1997) Predicting inhospital mortality of patients with AIDS-related Pneumocystis carinii pneumonia: An example of hierarchically optimal classification tree analysis. Statistics in Medicine 16:1451-1463

39. Yarnold PR, Soltysik RC (2005) Optimal data analysis: guidebook with software for Windows. APA Books, Washington, DC 